\section{Correlating Fluorescence Microscopy with Electron Microscopy}

\author{
Stephen W. Carmichael and Jon Charlesworth, 1 \\ Mayo Clinic carmichael.stephen@mayo.edu
}

The use of fluorescent probes is becoming more and more common in cell biology. It would be useful if we were able to correlate a fluorescent structure with an electron microscopic image. The ability to definitively identify a fluorescent organelle would be very valuable. Recently, Ying Ren, Michael Kruhlak, and David Bazett-Jones devised a clever technique to correlate a structure visualized in the light microscope, even a fluorescing cell, with transmission electron microscopy (TEM). ${ }^{2}$

Two keys to the technique of Ren et al. are the use of grids (as used in the TEM) with widely spaced grid bars and the use of Quetol as the embedding resin. The grids allow for cells to be identified between the grid bars, and in turn the bars are used to keep the cell of interest in register throughout the processing for TEM. Quetol resin was used for embedding because of its low autofluorescence and sectioning properties. The resin also becomes soft and can be cut and easily peeled from glass coverslips when heated to $70^{\circ} \mathrm{C}$.

For demonstrating the technique, Ren ef al. grew neuroblastoma cells on coverslips. After fixing and permeabilizing the cells, they were exposed to monoclonal antibodies for promyelocytic leukemia (PML) protein. The specimen was then treated with a second antibody that was tagged with a fluorophore. The coverslips were mounted on slides using a glycerol-based mounting media and the fluorescing cells (or cell) of interest were identified at high magnification then imaged at low magnification with a light microscope (LM), with or without fluorescence. After an image record of the cells had been made, a 50 mesh copper grid was positioned over the cells of interest and attached to the coverslip with transparent tape. The slicle was then returned to the LM and the exact location of the cells with respect to the 16 grid openings was noted. The coverslip was separated from the slide, placed in a $40-\mathrm{mm}$ petri dish, washed with phosphate buffered saline to remove the mounting media and processed for TEM.

For the final embedding step the coverslip (cells up) was covered with a thin layer $(0.5-2 \mathrm{~mm})$ of Quetol $651 \mathrm{mix}$ and polymerized. Once polymerized, a second grid was glued to the resin in register to the grid on the coverslip. The petri dish was placed on a hot plate at $70^{\circ} \mathrm{C}$. After a few minutes the resin softened and was cut within the perimeter of the coverslip with a scalpel. The cut resin was then carefully peeled off the coverslip. A third grid was placed on the cell side of the Quetol block in perfect register with the second grid. The region of interest was marked with a sharp scalpel and the grid opening was also marked with a felt-tip pen. A large selected area was cut with a razor blade and glued onto a blank bullet and mounted onto an ultramicrotome for sectioning.

When the block surface was lightly wiped with $95 \%$ ethanol, the cells could be seen and compared with images captured earlier with the fluorescence microscope. The exact cell(s) was identified, the block further trimmed, and thin sectioned. The grid with the sections was placed on a glass slide, covered with a coverslip, and imaged with a fluorescence microscope at low (to determine the position of the cell of interest with respect to the grid bars) and high (to obtain the highest resolution of fluorescence labeling present) magnification. The grid was then transferred to the electron microscope where conventional TEM and electron spectroscopic imaging were employed. Correlative fluorescence and ultrastructural images from the region $(s)$ of interest were compared and contrasted. With this method detail at the suborganelle level was obtained. We followed the methods of Ren et al. in our lab, and it worked on the first try.

It will be exciting to see the interesting uses for this advance in correlative microscopy!

The authors gratefully acknowledge Dr. David Brazett-Iones for reviewing this article. Jon Charlesworth is the Coordinator of the Electron Microscopy Core Facility at Mayo Clinic.

2 Ren, Y, M.J. Kruhlak, and D.P. Bazett-Jones, Same serial section correlative light and energy-filtered transmission electron microscopy, J. Histochem. Cytochem. 51:605-612, 2003.

\title{
InPax of AmTletes
}

Correlating Fluorescence Microscopy

with Electron Microscopy

Stephen W. Carmichael and Jon Charlesworth, Mayo Clinic

Electron Microscopy Enters a New Era Using Aberration Correction

P.E. Batson, IBM Research

Microscopy and Imaging of Foods - The Whys and Hows Paula Allan-Wojtas, Agriculture and Agri-Food Canada

Image Stitching Using Photoshop Jerry Sedgewick, University of Minnesota

A Few Thoughts About Image File Storage Michael Bode, Soft Imaging System Corp.

Behavior of Particle Size Distributions, Means and BET Values In Ideal and Non-Ideal Morphology Systems in a TEM 30 Paul Beauregard, Chemist and Electron Microscopist

The Moving Finger Writes: Carbon Nanotubes as AFM Probe Tips

Katerina Moloni, nPoint, Inc.

Confocal Microscopy System Performance: Axial Resolution 38 Robert M. Zucker, U.S. Environmental Protection Agency

Enhanced Sample Preparation of Cu Low-k Semiconductors via Mechanical Polishing and lon Beam Etching

Shane Roberts, Daniel Flatoff, South Bay Technology, Inc.

The Year That Wasl Microscopy in Southern Africa .44

Luc Harmsen, Anaspec, South Africa

\section{Comments on Cryo High Resolution Scanning}

Electron Microscopy .45

Robert P. Apkarian, IM\&MF/Emory University

Propylene Oxide: To Use or Not to Use in Biological

Tissue Processing

Jose A. Mascorro, Tulane University

Is Low Accelerating Voltage Always the Best for

Semiconductor Inspection and Metrology?

M. T. Postek and A. E. Vladár, National Institute

of Standards and Technology

Industry News

NetNotes.

Index of Advertisers.

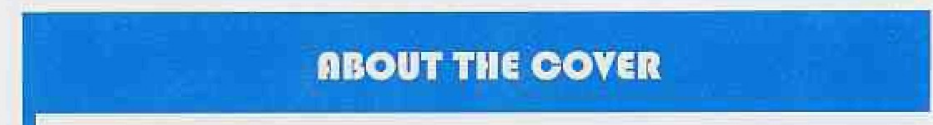

\section{Aberration Corrected, High Resolution Image P.E. Batson, IBM Research}

Annular Dark Field STEM image of a Au island on a carbon resolution test specimen using a 1 Angstrom probe. The data have been Fourier filtered to reduce noise. Single Au atoms, and monolayer "rafts" of Au atoms are visible nearby. The large Au island is about 50 Angstroms in diameter. 


\section{When $\mathrm{LN}_{2}$ is not practical}

\section{Introducing}

PGT Sahara SD Detector is quickly becoming the detector of choice for $X$-ray applications requiring excellent energy resolution, high count rate capability and low energy sensitivity, ....without liquid nitrogen!

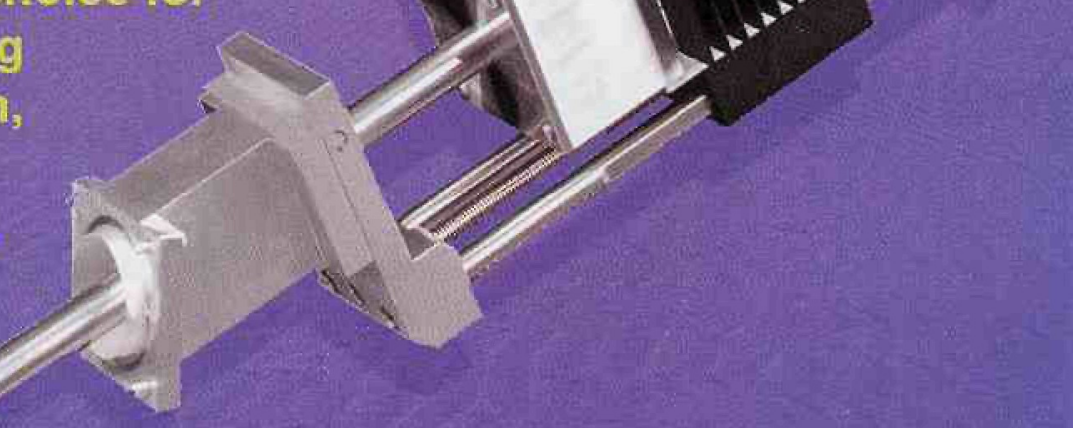

\section{Excellent Energy Resolution}

No liquid nitrogen, no water-cooling

No moving parts, or vibration

For more information visit our web site: www.pgt.com/sahara.html

Princelon Gamma-Tech, Inc. CN 863

Princeton, NJ 08542-0863

Web site: Www.pgt.com
Tel: (609) 924-7310

Fax: (609) 924-1729

Toll free: $800-229-7484$ e-mail: sales@pgt.com

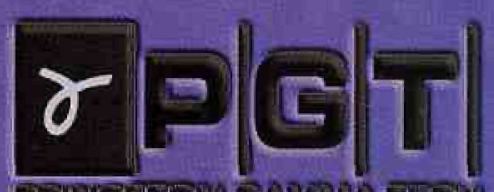

PRINEETOVI EAMNATECH 


\section{CRESSINGTON O 208 HR}

\section{High Resolution Sputter Coating}

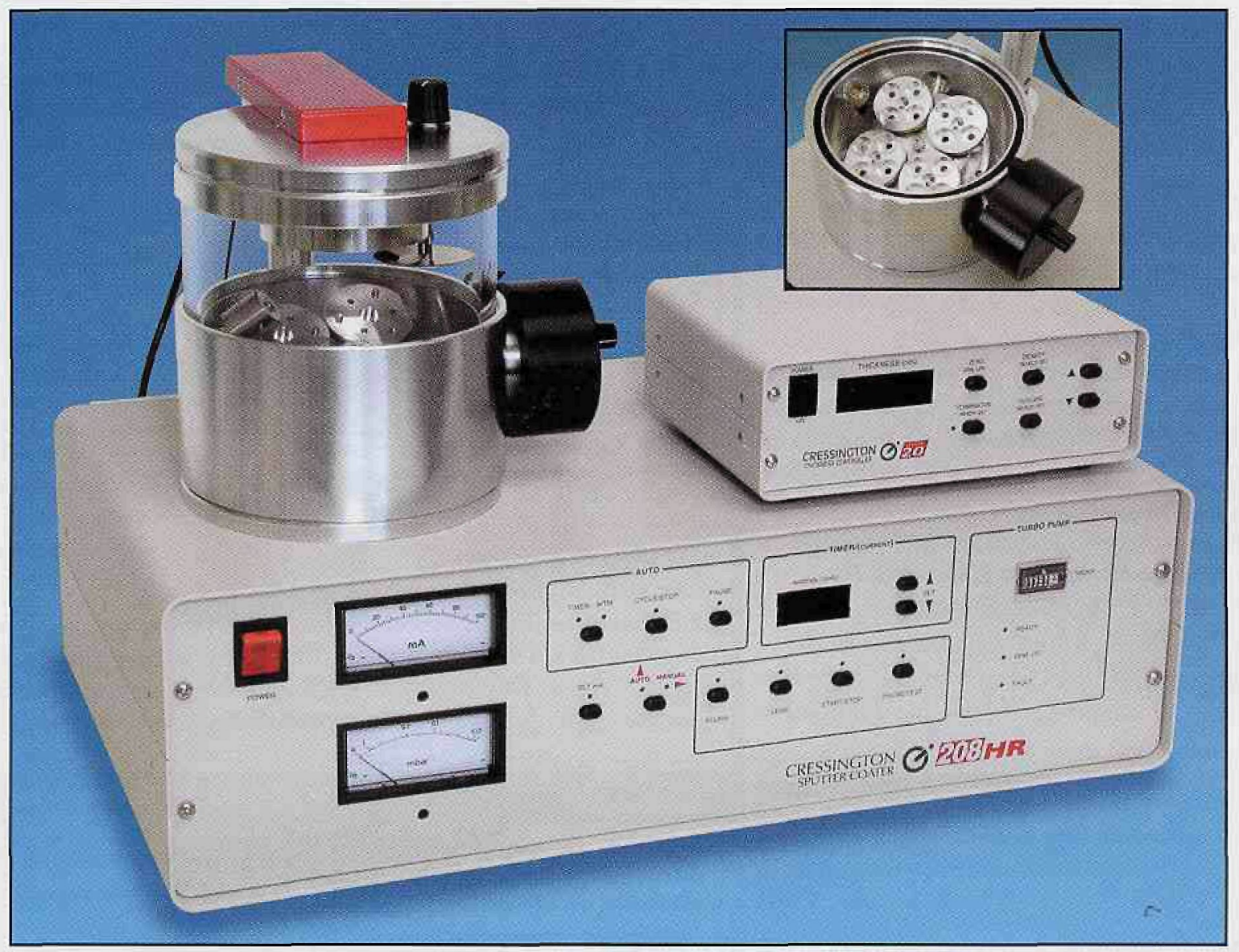

High Resolution Sputter Coater 208HR shown with Rotary-Planetary-Tilting Stage and Thickness Controller MTM-20 The Cressington 208HR offers the most sophisticated features in it's class, at an outstanding value

\section{Superior Features}

- Wide Choice of Coating Materials

Magnetron head design and effective gas handling allow a wide choice of target materials

- Precision Thickness Control

Thickness optimized to the FE-SEM operating voltage using the MTM-20 high resolution thickness controller

\section{- Multiple Sample Stage Movements}

Separate rotary, planetary and tilting movements allow optimized coating distribution and coverage

\section{- Variable Chamber Geometry}

Chamber geometry is used to adjust deposition rates from $1.0 \mathrm{~nm} / \mathrm{sec}$ to $0.002 \mathrm{~nm} / \mathrm{sec}$ to optimize structure

\section{- Wide Range of Operating Pressures}

Independent power / pressure adjustment allows operation at argon gas pressure ranges of $0.2-0.005 \mathrm{mbar}$

\section{- Compact Modern Benchtop Design}

Space and energy saving design eliminates need for floor space, water, specialized electrical connections

\section{Coating Difficult Samples for the FE-SEM}

The High Resolution Sputter Coater 208HR offers real solutions to the problems encountered when coating difficult samples for FE-SEM. In order to minimize the effects of grain size the $208 \mathrm{HR}$ offers a full range of coating materials and gives unprecedented control over thickness and deposition conditions. To minimize charging effects the $208 \mathrm{HR}$ stage design and wide range of operating pressures allows precise control of the uniformity and conformity of the coating. The HIGH/LOW chamber configuration allows easy adjustment of working distance.

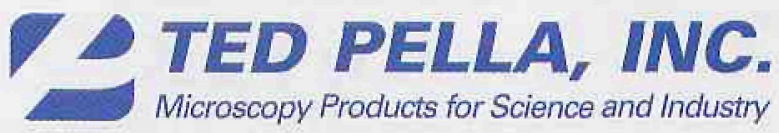

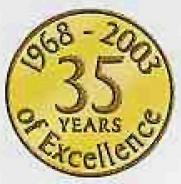




\section{coming avents}

\section{$\checkmark$ PITTCON 2004}

March 7-12, 2004, Chicago, IL

www.pittcon.org

$\checkmark$ TMS

March 14-18, 2004, Charlotte, NC

ckobert@tms.org

$\checkmark$ Advanced Course on Light Microscopy

March 22-26, 2004, University of California, Santa Barbara www.lifesci.ucsb.edu/madb/events/imaging_workshop/index.php

$\checkmark$ Focus on Microscopy 2004

April 4-7,2004, Philadelphia, PA

www.focusonmicroseopy.org

$\checkmark$ Materlals Research Society

April 12-16, 2004, San Francisco, CA

info(amrs.org

$\checkmark$ SCANNING 2004

April 27-29, 2004, Washington, DC

www.scanning.org

$\checkmark$ Asla-Pacific Congress on Electron Microscopy

June 7-11, 2004, Kanazawa, Japan

keih@kanazawa-med.ac.jp

$\checkmark$ 12th Int'l. Congress of Histochemistry and Cytochemistry

July 24-29, 2004, LaJolla, CA

www.ifschc.org/index2004.html/

$\checkmark$ CrYO-HRSEM/STEM/TEM

July 28-30, 2004, Atlanta, GA

rapkari@emory.edu

$\checkmark$ Microscopy and Microanalysis 2004

August 1-5, 2004, Savannah, GA

WwW.msa.microseopy.com

$\checkmark$ EMC 2004 (former EUREM)

August 22-27, 2004, Antwerp, Belgium

www.eme2004,be

$\checkmark$ Society for Neuroscience

October 23-28, 2004

info@sfn.org

2005

$\checkmark$ Materials Research Society

April 12-16, 2005, San Francisco, CA

info@mrs.org

$\checkmark$ Scanning 2005

May 5-7, 2005, Monterey, CA

scanning@fams.org

$\checkmark$ Microscopy and Microanalysis 2005

July 31 - August 4, 2005, Honolulu, HA

www.msa.microscopy.com

$\checkmark$ Materials Research Society

November 29-December 3, 2004, Boston, MA

info@mrs.org

$\checkmark$ American Society for Cell Biology 2003

December 4-8, 2004, Washington, DC

www.ascb.org

2006

$\checkmark$ Microscopy and Microanalysis 2006

August 6-10, 2006, Chicago, IL

www.msa.microscopy.com

Please check the "Calendar of Meetings and Courses" in the MSA journal

"Microscopy and Microanalysis" for more details and a much larger listing of meetings and courses.

\section{mIonosoopy TOPMY}

The objective of this publication is simply to provide material of interest and value to working microscopists!

The publication is owned by the Microscopy Society of America (MSA) and is produced six times each year in odd months, alternating with MSA's peer-reviewed, scientific journal Microscopy and Microanalysis. We greatly appreciate article and material contributions from our readers- "users" as well as manufacturers/suppliers. The only criterion is that the subject matter be of interest to a reasonable number of working microscopists. Microscopy Today has authors from many disparate fields in both biological and materials sciences, each field with it's own standards. Therefore $M T$ does not have a rigid set of style instructions and encourages authors to use their own style, asking only that the writing be clear, informative, and accurate. Length: typical article length is 1,500 to 2,000 words plus images, Longer articles will be considered. Short notes are encouraged for our Microscopy 101 section.

\section{MICROSCOPY TODAY}

\author{
Ron Anderson, Editor \\ ron.anderson@attglobal.net
}

José Mascorro, Technical Editor

jmascor@tulane.edu

Dale Anderson, Art Director

dale.anderson@attglobal.net

Regular Mail to:

PO Box 499

Wappingers Falls, NY 12590

Courier Mail to:

21 Westview Drive

Poughkeepsie, NY 12603

Telephones:

1-(845)463-4124 - Fax: (845)463-4125 - Cell: (914) 453-2917

e-Mail:

microtoday@attglobal.net

WWW Page:

http://wwwimicroscopy-today.com

Disclaimer: By submitting a manuscript to Microscopy Today, the author warrants that the article is original (or that the author has the right to use any material copyrighted by others). The use of trade names, trademarks, etc., does not imply that these names lack protection by relevant laws and regulations. Microscopy Today, the Microscopy Society of America, and any other societies stated, cannot be held responsible for opinions, errors, or for any consequences arising from the use of information contained in Microscopy Today. The appearance of advertising in Microscopy Today does not constitute an endorsement or approval by the Microscopy Society of America of the quality or value of the products advertised or any of the claims, data, conclusions, recommendations, procedures, results or any information found in the advertisements. While the contents of this magazine are believed to be accurate at press time, neither the Microscopy Society of America, the editors, nor the authors can accept legal responsibility for errors or omissions.

c) Copyright, 2004, The Microscopy Society of America. All rights reserved. 
